\title{
М.Е. Романова
}

Центр образования "Business Lingual English Studying Center", 101996, г. Москва, Российская Федерация

\section{Позитивная социализация детей старшего дошкольного возраста в процессе развития диалогической речи}

Статья посвящена теории и методике позитивной социализации детей старшего дошкольного возраста осреством развития диалогической речи. В предлагаемой программе и методике акцент делается не только на умения строить диалог в вопросно-ответной форме, но и на умения оптимального аудирования (слышать собеседника, делать реплики-реакции в соответствии с услышанным, изменять ход беседы, не отступая от ее основной темы), а также этикетные и поведенческие умения. Программа прошла эмпирическую проверку, чем подтвердила свою эффективность.

Ключевые слова: социализация дошкольника, развитие диалогической речи, дети дошкольного возраста, эмоциональный интеллект, самооценка, самостоятельность, социальная успешность

ССЫЛКА НА СТАТЬЮ: Романова М.Е. Позитивная социализация детей старшего дошкольного возраста в процессе развития диалогической речи // Педагогика и психология образования. 2020. № 3. C. 147-158. DOI: 10.31862/2500297X-2020-3-147-158 
DOI: 10.31862/2500-297X-2020-3-147-158

\section{Romanova}

Education Centre "Business Lingual English Studying Center", Moscow, 101996, Russian Federation

\section{Positive socialization of older pre-school children in the process of dialogue speech development}

The article deals with the theory and methodology of positive socialization of older pre-school children in the process of dialogue speech development. The proposed programme and methodology focus not only on the ability to communicate in a question-and-answer manner, but also on the ability to optimize the response (to hear the interlocutor, to make replicas according to the heard, to change the course of the conversation, not departing from its main theme) as well as etiquette and behavioral skills. The program has been empirically tested and proven to be effective.

Key words: socialization of a preschooler, development of dialogical speech, preschool children, emotional intelligence, self-esteem, independence, social success

CITATION: Romanova M.E. Positive socialization of older pre-school children in the process of dialogue speech development. Pedagogy and Psychology of Education. 2020. No. 3. Pp. 147-158. (In Russ.). DOI: 10.31862/2500-297X-20203-147-158

Под социализацией в отечественной дошкольной педагогике понимается развитие у ребенка широкого спектра социальных компетенций, принципиально важных для адаптации к социальной среде и жизни в обществе. К основным функциям процесса социализации ребенкадошкольника большинство исследователей относят: усвоение и воспроизводство социального опыта, а также социальное творчество как условие будущих социальных изменений (Е.Н. Волкова, Т.В. Вереитинова, И.В. Волкова, О.С. Михалюк) [4]. Имеющее место в последние десятилетия активное взаимодействие российских и зарубежных ученых, 
проведение кросс-культурных исследований привели к введению в отечественный научный дискурс понятия «позитивная социализация», занявшего особое место в ряду психолого-педагогических понятий.

Со времен выхода работы Л.С. Выготского: «История развития высших психических функций» (1931) в отечественной детской психологии и педагогике в качестве центрального утвердилось положение о том, что овладение ребенком социальным опытом и своим поведением происходит преимущественно благодаря развитию речи. Для современной дошкольной педагогики остается бесспорным факт, что на ранних этапах социализации личности эффективность этого процесса во многом зависит от освоения устной речи, в частности речи диалогической. Развитие диалогической речи мы рассматриваем в качестве одного из важнейших факторов позитивной социализации личности ребенка старшего дошкольного возраста.

В нашем исследовании мы опирались на результаты многочисленных исследований речи как одной из высших психических функций, а также итоги исследований языка как продукта эволюции культуры и средства общения (Л.С. Выготский, И.С. Кон, А.Н. Леонтьев, А.А. Леонтьев, С.Л. Рубинштейн, Т.Н. Ушакова, А.Н. Хомский и др.). Не менее важным основанием нашей работы являются лингвистические положения о специфике и своеобразии диалогической формы речи (Е.А. Брызгунова, Т.Г. Винокур, А.В. Щерба, Л.П. Якубинский и др.).

Методика работы по развитию речи, формированию и развитию компетенций у будущих и действующих педагогов постоянно совершенствуется и пополняется новыми знаниями за счет достижений дошкольной дидактики, психологии, психолингвистики и социолингвистики. В современных методических системах акцент делается не только на умения детей строить диалог в вопросно-ответной форме, но также на способности к оптимальному аудированию (слышать собеседника, делать реплики-реакции в соответствии с услышанным, изменять ход беседы, не отступая от ее основной темы), этикетные и поведенческие навыки. С учетом этого нами была разработана программа позитивной социализации детей старшего дошкольного возраста в процессе развития диалогической речи, эффективность которой была проверена в ходе эксперимента.

Экспериментальная работа по проверке эффективности программы проводилась на базе ГБОУ города Москвы «Школа № 2103». В исследовании приняли участие 65 детей старшего дошкольного возраста: 32 ребенка в контрольной группе и 33 в экспериментальной.

Диагностика уровней позитивной социализации и развития диалогической речи детей старшего дошкольного возраста была проведена 
в экспериментальной и контрольной группах до и после реализации экспериментальной программы. Оценка уровней позитивной социализации детей старшего дошкольного возраста проводилась по параметрам: эмоциональный интеллект; самооценка; самостоятельность; социальная успешность. Оценка осуществлялась методом наблюдения в сочетании с методом экспертов. Для оценки уровня развития диалогической речи использовалась методика М.М. Алексеевой и В.И. Яшиной [2]. Основное внимание уделялось оценке различных критериев:

1) коммуникабельность ребенка (желание выполнять задание, активность общения, легкость контактирования);

2) экспрессивность общения: использование мимики, пантомимики и других невербальных проявлений; эмоциональное состояние, интонационная выразительность;

3) степень самостоятельности, использование помощи при выполнении заданий;

4) полнота изложения, смысловое соответствие воспроизводимого материала заданному образцу, связность и логичность высказывания;

5) речевые средства, с помощью которых реализуются высказывания детей: лексическая полнота и грамматическая правильность, типы предложений.

Результаты диагностики уровней позитивной социализации и развития диалогической речи у детей старшего дошкольного возраста в обеих группах на начальном, диагностическом этапе представлены на рис. 1.

Рисунок 1 наглядно показывает, что на начальном, диагностическом этапе эксперимента до применения в экспериментальной группе специальной программы по позитивной социализации путем развития диалогической речи старших дошкольников, диагностические оценки детей экспериментальных и контрольных групп оказались практически идентичными, что свидетельствует о равных уровнях развития детей экспериментальной и контрольной групп до начала формирующего этапа исследования.

После проведения диагностического этапа исследования в экспериментальной группе была реализована разработанная программа позитивной социализации на основе развития диалогической речи у старших дошкольников. В это время контрольная группа старших дошкольников, участвовавших в нашем исследовании, работала по традиционной для дошкольных образовательных организаций модели, где также по-своему решались задачи позитивной социализации и развития диалогической речи.

В ходе формирующего этапа исследования нами была проверена эффективность разработанной программы, ориентированной на социализацию детей старшего дошкольного возраста путем развития у них 
диалогической речи. При создании программы использовались результаты исследования процесса позитивной социализации личности, основу которой составляет социальный интеллект (О.А. Айгунова, Н.Б. Полковникова, А.И. Савенков, Т.Д. Савенкова [1], С.И. Карпова, Е.И. Сухова [6]), а также научные разработки в области теории и методики развития речи детей старшего дошкольного возраста (А.Г. Арушанова, Т.И. Бабаева, Л.А. Венгер, В.В. Гербова, А.В. Запорожец, Ф.А. Сохин, Е.И. Тихеева, О.С. Ушакова и др.). Не менее важным источником при разработке нашей программы стали методические решения педагогов-практиков дошкольных образовательных организаций [2; 3].

Доля детей в группе, \%

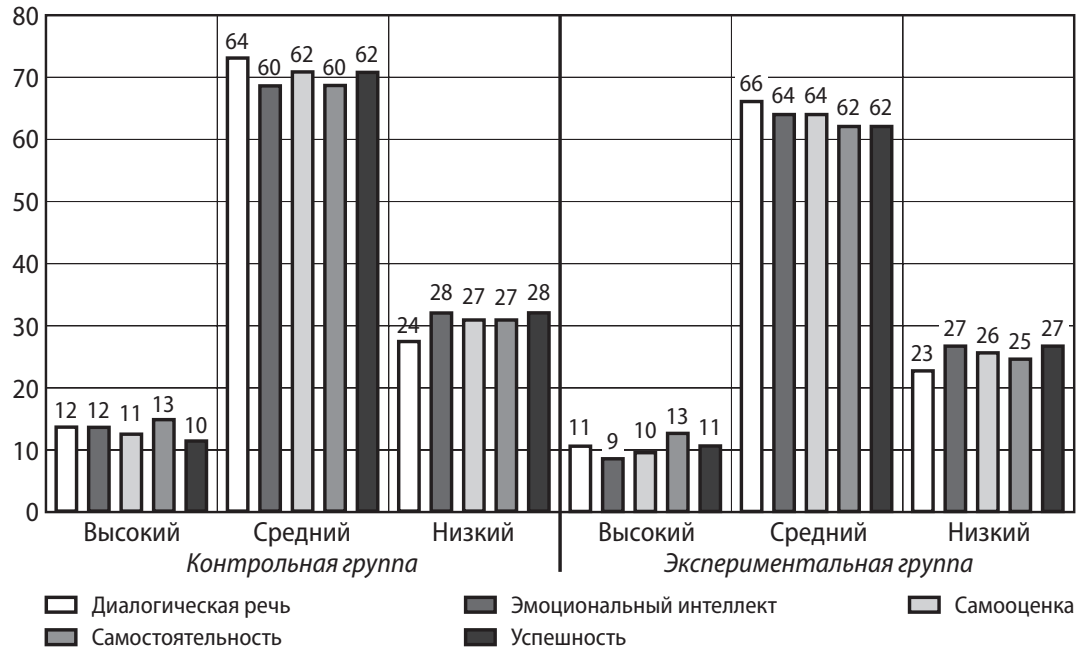

Рис. 1. Результаты диагностики уровней позитивной социализации и развития диалогической речи детей старшего дошкольного возраста на диагностическом этапе исследования

Цель разработанной программы заключалась в создании условий для позитивной социализации детей старшего дошкольного возраста путем развития у них диалогической речи. Для реализации поставленной цели нами были выделены задачи, которые легли в основу разработки методических материалов:

1) разработать комплекс специальных заданий, позволяющих постепенно и последовательно усложняя и стимулируя речевое общение, развивать социальные контакты старших дошкольников;

2) создать систему последовательного обучения детей старшего дошкольного возраста нормам и правилам построения диалогической речи; 
3) создать условия, активизирующие самостоятельное, спонтанное общение детей старшего дошкольного возраста со сверстниками и взрослыми;

4) создать условия для повышения социального статуса ребенка в коллективе сверстников путем корректировки его самооценки и стимулирования речевых контактов со сверстниками и взрослыми;

5) способствовать развитию диалогической речи детей путем создания условий для осознания «ситуаций успеха» в ходе речевого взаимодействия со сверстниками и взрослыми.

Реализация программы проводилась в традиционных направлениях: общепедагогическом, психопрофилактическом и психокоррекционном. В ходе ее реализации были задействованы все участники образовательного процесса: педагоги-воспитатели, практические психологи, логопеды дошкольных образовательных организаций, дети и их родители. На каждого из участников была возложена особая миссия, связанная с его профессиональной компетентностью, особая роль отводилась педагогическому, психологическому и методическому просвещению родителей. Осуществлялось оно преимущественно в форме индивидуальных бесед, проводимых как по инициативе сотрудников детской образовательной организации, так и по запросам самих родителей.

Программа позитивной социализации личности ребенка старшего дошкольного возраста, построенная нами на основе совершенствования его диалогической речи, состояла из модулей. Первый модуль программы включал специальные занятия по развитию речи, обычно осуществляемые в дошкольном образовательном учреждении. В ходе этих занятий, с помощью специально разработанных заданий, педагоги целенаправленно работали над задачей позитивной социализации детей в процессе воспитания, обучения и развития у них речевой культуры, умений и навыков построения диалогической речи. Эта часть программы предполагала использование традиционных и инновационных форм организации занятий и методических приемов, обычно используемых педагогами и логопедами в работе со старшими дошкольниками: сюжетно-ролевые игры; игры-драматизации; рассказы по картинкам; заучивание и декламирование стихов-диалогов; проигрывание инсценировок, участие в спектаклях, обсуждение детских книг и мультфильмов.

Например, умения детей задавать вопросы и отвечать на них отрабатывались на занятиях с использованием игровых приемов: «да и нет»; «вопросы с подсказкой»; «запрещенные слова»; «смешинка»; «турнир знатоков»; «ты мне - я тебе» и др. Участие в подобных игровых ситуациях требует от дошкольников мобилизации когнитивных способностей, активизации знаний об отношениях людей, о природе, родном 
городе и т.п. Например, в игре «да и нет» детей побуждали к построению вопросов в определенной логической последовательности. Дети задают цепочку вопросов, чтобы, получая в ответ лишь «да» и «нет», догадаться, какой предмет, животное или растение «спрятано» в волшебном сундучке. Точность формулировок вопросов зависит от ясности представлений ребенка о предметах или животных, об их основных классификационных признаках.

При составлении повествовательного рассказа по картинке или серии сюжетных картинок детям предлагалось указать время и место изображенного на ней действия, назвать действующих лиц (желательно дать им имена), охарактеризовать их, описать само происшествие, предположить исход события. Дети с удовольствием составляли рассказы по картинкам с изображением диких и домашних животных (темы: «упрямые козлы», «заводная мышка», «добрая утка» и др.).

Для заучивания диалогов нами были подобраны небольшие стихотворения с частой сменой реплик, с использованием диалогических единств «вопрос - ответ», «сообщение - реакция на сообщение» (например: А. Барто «Я знаю, что можно придумать», С. Маршак «Перчатки», А. Берлов «Лягушонок», Н. Сладков «Разговор лисы и зайца»).

В качестве примера игры-драматизации представляем фрагмент занятия - «Карлсон». Ведущий предлагает детям отгадать загадку:

\section{Мой дом - у вас на крышие! \\ Я каждому знаком! \\ И мой пропеллер сльшен \\ Над вашим чердаком!}

(автор загадки М. Танич)

Детям ставятся задачи: одному ребенку - показать, какое лицо у Карлсона, другому - какое довольное лицо у мальчика, к которому прилетел Карлсон. В таких играх развиваются важные составляющие эмоционального интеллекта: умения адекватно выражать собственные эмоции; понимать эмоции и мотивы поведения других людей. Совершенствуются навыки использования невербальных средств общения в процессе диалога.

Не менее важными инструментами при решении задач позитивной социализации детей в процессе развития у них диалогической речи были используемые в нашей программе обсуждения с детьми событий дня, книг, мультфильмов. Педагог-экспериментатор анализировал речевую активность детей в разнообразных ситуациях повседневной жизни. Например, при ответе ребенка на вопрос: «Какое событие дня тебе запомнилось и почему?» педагогом-экспериментатором фиксировалась 
и уточнялась степень самостоятельности и способность к адекватной оценке собственной успешности (примеры высказываний: «Я сегодня лучше всех делал зарядку», «Меня похвалил воспитатель на занятии по лепке»). При ответе на вопрос: «Как бы ты поступил на месте героя мультфильма?» педагог имел возможность диагностировать и корректировать самооценку ребенка, являющуюся важным компонентом его позитивной социализации.

В программе подобраны упражнения на поэтапную отработку диалогических единств «побуждение - реакция на побуждение», «вопрос ответ», «сообщение - реакция на сообщение». Во время выполнения данных упражнений в процессе формирующего этапа эксперимента равное внимание уделялось позитивной социализации и формированию лингвистических и коммуникативных навыков.

Второй модуль нашей программы предполагал использование в качестве методических инструментов различных вариантов построения детьми речевого взаимодействия на занятиях по всем предметным областям, предусмотренным Государственным образовательным стандартом дошкольного образования Российской Федерации. Имеются в виду занятия различной предметной направленности, организуемые педагогами и практическими психологами дошкольных образовательных организаций (игровая, коммуникативная, познавательно-исследовательская, самообслуживание и элементарный бытовой труд, конструирование из различных материалов, изобразительная, музыкальная, двигательная).

Задача третьего модуля программы, по замыслу нашего исследования, должна была охватить множество самых разных аспектов жизнедеятельности и социального взаимодействия детей, как в дошкольной образовательной организации, так и за ее пределами. Здесь активными участниками работы по позитивной социализации детей старшего дошкольного возраста в ходе диалогического общения, кроме специалистов дошкольных образовательных организаций (педагогов, логопедов, психологов), становились родители.

В содержание первого модуля программы были включены специально подобранные и авторские задания и упражнения на поэтапную отработку диалогических единств: «побуждение - реакция на побуждение», «вопрос - ответ», «сообщение - реакция на сообщение». Во время выполнения таких заданий и упражнений равное внимание педагоги-экспериментаторы уделяли развитию у детей общих коммуникативных навыков, базовых параметров социального интеллекта детей (социальные знания, социальная интуиция, адекватное выражение собственных и понимание чужих эмоций, саморегуляция своих речевых 
и поведенческих реакций и др.) [5]. Не меньшее внимание уделялось и вопросам формирования и развития общих лингвистических знаний, умений и навыков.

Затем на заключительном, контрольном этапе эксперимента нами было проведено итоговое обследование детей. Результаты представлены на рис. 2 и 3. Представленные графики позитивной социализации и уровней развития диалогической речи у детей старшего дошкольного возраста показывают динамику в контрольной и экспериментальной группах до и после экспериментальной работы. Анализ содержащихся в них результатов показывает, что в экспериментальной группе наблюдается увеличение количества детей, имеющих высокий и средний уровень развития по измеряемым параметрам. Кроме того, в экспериментальной группе снизился процент дошкольников с низким уровнем изучаемых параметров. По-прежнему наибольший процент в обеих группах составляют дети со средним уровнем развития диалогической речи.

Доля детей в группе, \%

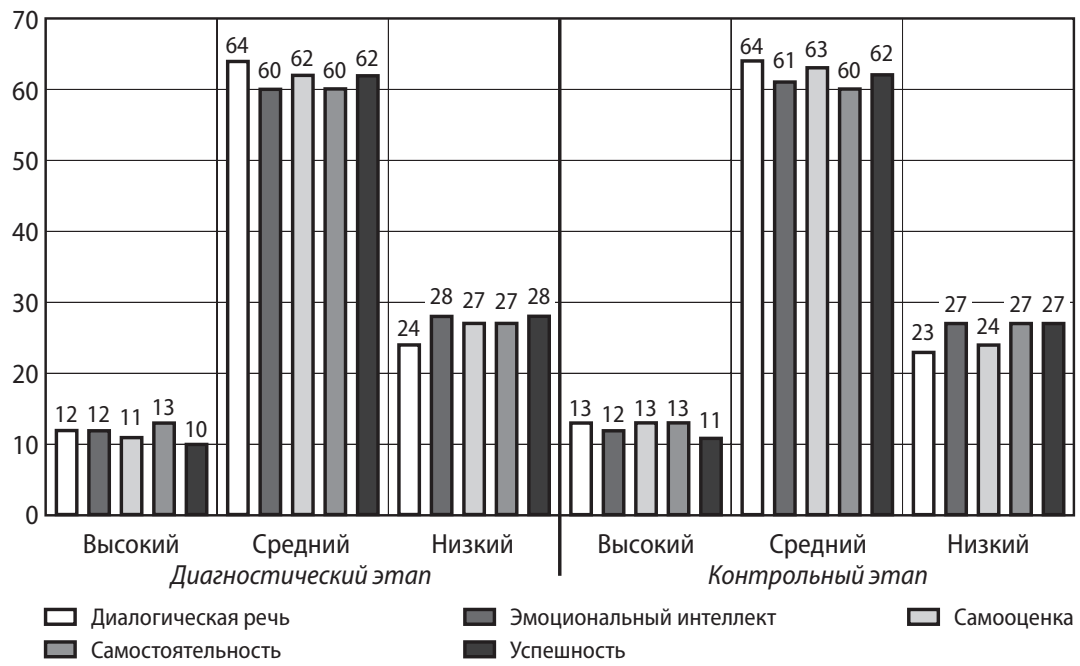

Рис. 2. График динамики позитивной социализации и уровней развития диалогической речи детей старшего дошкольного в контрольной группе на диагностическом и контрольном этапах работы

Анализируя данные, полученные в результате диагностики респондентов контрольной группы (см. рис. 2) на начальном (диагностическом) и завершающем (контрольном) этапе эксперимента, мы можем отметить: процент детей с высоким уровнем развития диалогической 
речи незначительно вырос; процент респондентов со средним уровнем развития диалогической речи и позитивной социализации также показал незначительный прогресс. Явно выраженной положительной или же отрицательной динамики по параметрам позитивной социализации и уровню развития диалогической речи детей старшего дошкольного возраста из контрольных групп не наблюдается.

На рис. 3 представлены результаты динамики позитивной социализации и уровней развития диалогической речи детей старшего дошкольного в экспериментальной группе на диагностическом и контрольном этапах работы.

Доля детей в группе, \%

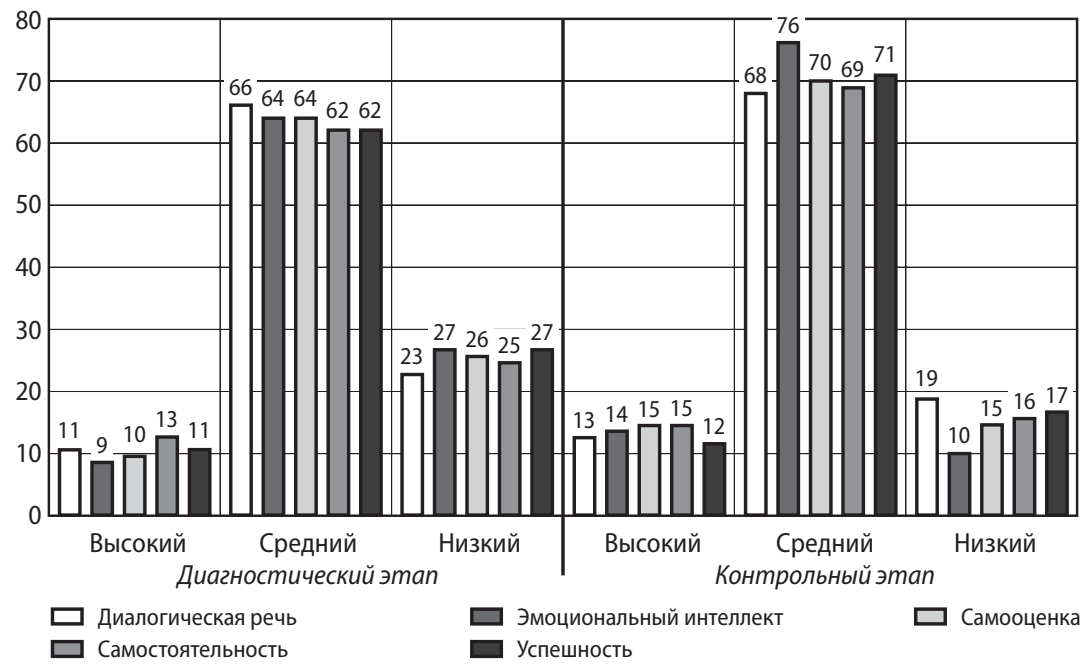

Рис. 3. График динамики позитивной социализации и уровней развития диалогической речи детей старшего дошкольного в экспериментальной группе на диагностическом и контрольном этапах работы

Представленные на рис. 3 результаты обследования детей из экспериментальных групп после проведения формирующего этапа исследования, в ходе которого была внедрена в образовательный процесс дошкольной образовательной организации разработанная нами программа развития позитивной социализации и диалогической речи, свидетельствуют о том, что позитивные изменения в уровнях изучаемых параметров, по сравнению с результатами детей из контрольной группы, более очевидны. Рост показателей позитивной социализации и развития диалогической речи в экспериментальной группе более 
значителен. Процент детей с высоким уровнем позитивной социализации и развития диалогической речи вырос после проведения формирующего этапа экспериментальной работы. При этом, за счет нашей программы, внедренной в образовательный процесс экспериментальной группы, на формирующем этапе исследования процент детей со средним уровнем изучаемых характеристик вырос. Произошло это за счет детей, которые на первом (контрольном) этапе исследования показали низкий уровень позитивной социализации и низкий уровень освоения диалогической речи. Также в экспериментальной группе снизился процент детей с низким уровнем позитивной социализации и уровнем развития диалогической речи.

При статистическом сравнении на основе t-критерия Стьюдента (расчет производился в программе SPSS Statistics) было подтверждено, что различия на контрольном этапе эксперимента между экспериментальной и контрольной группой статистически значимы на уровне значимости $\alpha=0,05$. Это позволяет утверждать, что данные различия обусловлены внедрением программы позитивной социализации детей старшего дошкольного возраста в процессе развития диалогической речи.

Полученные в ходе эксперимента данные свидетельствуют о том, что поставленные задачи выполнены, данную программу можно рекомендовать для работы по позитивной социализации детей старшего дошкольного возраста в процессе развития у них диалогической речи в дошкольных образовательных организациях.

\section{Библиографический список / References}

1. Айгунова О.А., Полковникова Н.Б., Савенкова Т.Д. Диагностика и развитие эмоционального интеллекта и социальной компетентности старших дошкольников в условиях дошкольной образовательной организации // Вестник Московского городского педагогического университета. Серия: Педагогика и психология. 2016. № 4 (38). С. 25-34. [Aygunova O.А., Polkovnikova N.B., Savenkova T.D. Diagnostics and the development of emotional intelligence and social competence of the older preschoolers in the conditions of preschool educational institution. Vestnik of Moscow City University. Series «Pedagogy and Psychology». 2016. No. 4 (38). Pp. 25-34. (In Russ.)]

2. Алексеева М.М., Яшина В.И. Методика развития речи и обучения родному языку дошкольников. М., 2010. [Alekseeva M.M., Yashina V.I. Metodika razvitiya rechi i obucheniya rodnomu yazyku doshkolnikov [Methodology of developing speech and teaching the native language of preschoolers]. Moscow, 2010.]

3. Бизикова О.А. Развитие диалогической речи дошкольников в игре. М., 2008. [Bizikova O.A. Razvitie dialogicheskoy rechi doshkolnikov v igre 
[Development of dialogical speech of preschoolers in the game]. Moscow, 2008.]

4. К определению понятия позитивной социализации молодежи / Е.Н. Волкова, Т.В. Вереитинова, И.В. Волкова, О.С. Михалюк // Вестник Мининского университета. 2016. № 2. С. 1-9. [Volkova E.N., Vereinitova T.V., Volkova I.V., Mikhalyuk O.S. On definition of youth positive socialization. Vestnik of Minin University. 2016. No. 2. Pp. 1-9. (In Russ.)]

5. Савенкова Т.Д. Методика диагностики базовых параметров эмоционального интеллекта дошкольника // Вестник Московского городского педагогического университета. Серия: Педагогика и психология. 2017. № 3 (41). C. 47-53. [Savenkova T.D. The methods of diagnostics of basic parameters of emotional Intelligence of a preschooler. Vestnik of Moscow City University. Series "Pedagogy and Psychology". 2017. No. 3 (41). Pp. 47-53. (In Russ.)]

6. Savenkov A., Karpova S.I., Sukhova E.I. Model of development of children's giftedness in the Russian education system. Psychology (Savannah, Ga.). 2018. Vol. 55. No. 2. Pp. 74-84.

Статья поступила в редакцию 15.03.2020, принята к публикации 24.04.2020

The article was received on 15.03.2020, accepted for publication 24.04.2020

\section{Сведения об авторе / About the author}

Романова Мария Евгеньевна - педагог, Центр образования "Business Lingual English Studying Center”, г. Москвы

Maria E. Romanova - teacher, Business Lingual English Learning Center, Moscow

E-mail: romanovamarie@mail.ru 